\title{
Pulmonary prognosis in preterm infants
}

\author{
Luciana Friedrich, ${ }^{1}$ Andréa L. Corso, ${ }^{1}$ Marcus H. Jones ${ }^{2}$
}

\begin{abstract}
Objective: The increased survival of preterm infants poses the challenge of dealing with a wide range of chronic pulmonary diseases, including bronchopulmonary dysplasia, Wilson-Mikity syndrome and recurrent wheezing. This article reviews the pulmonary clinical and functional prognosis of preterm newborns in infancy and adolescence.

Source of data: MEDLINE search for articles published between 1970 and 2004 that focused on lung growth and function of preterm infants, besides a clinical follow-up of this group.

Summary of the findings: Prenatal and postnatal events, such as placental insufficiency, tobacco exposure, infections, oxygen and mechanical ventilation, have an important effect on lung development and can lead to chronic lung diseases, of which bronchopulmonary dysplasia is the most severe complication. However, significant loss of lung function occurs in preterm infants who do not fulfill the criteria for bronchopulmonary dysplasia, and even in those who did not have significant respiratory disease during the neonatal period. The impact of prematurity on the respiratory system of these patients is usually underestimated. Clinically, preterm infants have an increased incidence of pneumonia and bronchiolitis, hospital readmissions due to respiratory diseases, chronic cough and wheezing and bronchial hyperresponsiveness. In adolescence, there is a tendency for normalization of the lung function, but they persist with reduced flows, lower exercise tolerance and bronchial hyperresponsiveness.

Conclusions: Prematurity, the events that cause it and the interventions that follow it permanently change the development of the respiratory system. Studies are necessary to clarify the effect of each of these perinatal insults on the development of the respiratory system.
\end{abstract}

J Pediatr (Rio J). 2005;81(1 Suppl):S79-S88: Premature infant, bronchopulmonary dysplasia, spirometry, breath tests, hyaline membrane disease.

\section{Introduction}

Over the last twenty years the development of new neonatal intensive care techniques has offered a significant increase in preterm infant survival rates. Increased knowledge about neonatal physiology and pathology, routine use of corticoid therapy for expectant mothers in imminent danger of going into premature labor, the introduction of therapies such as exogenous surfactant

1. MSc in Pediatrics. Pontifícia Universidade Católica do Rio Grande do Sul (PUCRS), Porto Alegre, RS, Brazil.

2. PhD in Pneumology. Universidade Federal do Rio Grande do Sul (UFRGS), Porto Alegre, RS, Brazil.

Suggested citation: Friedrich L, Corso AL, Jones MH. Pulmonary prognosis in preterm infants. J Pediatr (Rio J). 2005;81 (1 Suppl):S79-S88. and new antimicrobial lines, in addition to new methods of ventilatory support, have resulted in ever more extremely premature infants survive childhood and successfully reach adulthood. Recent data demonstrated an increase of up to $80 \%$ in the survival of premature infants born at weights between 500 and $750 \mathrm{~g},{ }^{1}$ with around $75 \%$ of premature infants born at 26 to 27 weeks' gestational age at tertiary centers survive to 5 years of age. $^{2}$ In this context, the principal cause of mortality for this subset is no longer immaturity, but chronic lung disease, meaning that more babies survive the neonatal period, but present later morbidity and mortality, due to sequelae of prematurity such as bronchopulmonary dysplasia (BPD). ${ }^{1}$ Thus, the survival of ever more premature infants has progressively increased the incidence of chronic pulmonary diseases. ${ }^{3-5}$ 
Obstructive pulmonary diseases, ranging from recurrent coughing and wheezing to respiratory failure, remain significant complications of prematurity. ${ }^{6-7}$ This article takes as its objective a review of the pulmonary prognosis (clinical and functional) of premature infants through childhood and adolescence.

\section{Intrauterine development of the respiratory system}

The respiratory system undergoes significant structural changes during intrauterine development. ${ }^{8-9}$ The airways are completely formed very early, at around 16 weeks' gestational age, during the pseudoglandular stage of fetal pulmonary development. Between the 16th and 24th weeks, during the canalicular stage, these conductive structures increase in caliber, and during the saccular stage, between 24 and 36 weeks, the pre-acinar airways grow, the bronchioles develop and the acini are formed. The airways continue growing after birth, doubling their diameter and tripling their length by adulthood.

The alveoli, on the other hand, only begin to develop at around 28 weeks' gestation during the saccular pulmonary development phase, continuing to develop up to 3 years postpartum and continue multiplying and increasing in volume until the start of adulthood. ${ }^{10}$

Taking this pattern of development into account, it is to be expected that prenatal and early postnatal factors have an important effect on later pulmonary growth. It is known that any stage of respiratory system development can be susceptible to damage from many different mechanisms with risks of altering the normal pattern of development. ${ }^{10}$

A number of different factors have been described as being capable of affecting the immature pulmonary systems of preterm newborn babies, thus altering the development of respiratory tracts, alveolarization and the formation of pulmonary microvasculature. The principal prenatal factors that determine fetal pulmonary development are fetal growth and the duration of pregnancy. It is, however, difficult to differentiate pulmonary damage resulting from prematurity in isolation from damage secondary to ventilatory interventions during the neonatal period, since the two are intimately related. Other factors, such as hypoxia, placental insufficiency and smoking can also have a direct effect on normal pulmonary growth and development. ${ }^{10}$

\section{Postnatal pulmonary growth}

Postnatal factors that can interfere with normal pulmonary development are much more difficult to assess since there are no studies of function immediately before and after potentially adverse perinatal exposures. Nevertheless, certain factors, such as the development of the neonatal immune system and local airway responses to irritant and, in particular, infectious agents appear to be associated with reduced pulmonary function in fullterm infants and should be considered as relevant to later pulmonary prognosis. ${ }^{10}$
The physiological alterations that take place in the cardiocirculatory system after birth mean that premature infants are exposed early to factors that are potentially prejudicial to their structurally immature lungs. The extrauterine environment triggers active respiration, an abrupt drop in pulmonary vascular resistance and a significant increase in the perfusion of blood to these organs, in addition to exposure to oxygen $\left(\mathrm{O}_{2}\right)$ concentrations considerably higher than those of intrauterine life. The need for mechanical ventilation (MV) increases the risk of lung damage from oxygen free radicals, and exposure to large volumes and peak inspiratory pressures (PIP) can cause barotrauma with resulting injury to the respiratory epithelium. Studies with animals have shown that MV and exposure to high oxygen concentrations can induce a reduction in the formation and development of alveoli, provoking a series of histopathological findings characteristic of the phenomenon known as BPD. ${ }^{11}$

The process involved in repair of respiratory system, damage is generally called "remodeling". Little is known about the varying remodeling patterns that take place in the immature respiratory system, changing according to the developmental stage that is affected. It does, however, appear to be clear that this remodeling takes place within several different important lung structures, including the epithelium, the extracellular matrix, smooth musculature and mucus secretion. ${ }^{10}$

Therefore, many different perinatal factors can trigger a sequence of events which will lead to the development of persistent structural abnormalities and, consequently, to an increased incidence of later respiratory morbidity.

\section{Chronic lung disease of prematurity}

The diagnosis of chronic lung disease of prematurity (CLDP) covers a wide spectrum of respiratory conditions resulting from prematurity, such as distinct BPD presentations, Wilson-Mikity syndrome and recurrent wheezing associated or not with gastroesophageal reflux. ${ }^{12}$ Clinically, CLDP ranges from apparently healthy newborn babies with no significant neonatal respiratory events, but who exhibit ventilatory function losses, to newborn babies with severe ventilatory disorders who are dependent of oxygen.

The most severe clinical complication observed among survivors of neonatal respiratory diseases is BPD, which is easily diagnosed by prolonged oxygen dependency and characteristic radiological findings. ${ }^{13,14}$ This pathology was first described by Northway et al. in $1967 .{ }^{14}$ Later, in 1979, Bancalari15 described a new presentation of the pathology, called "new BPD", in which premature infants develop the pathology without previous hyaline membrane disease (HMD) and MV. ${ }^{16}$ This new BPD phenotype appears to principally manifest as reduced alveolar development rather than as airway damage, manifesting through more subtle signs, such as tachypnea and prolonged oxygen requirement. 17 
Currently two definitions of BPD continue to be used, of which the second seems to better predict long-term pulmonary prognosis: ${ }^{18}$

- Oxygen dependency and characteristic radiology findings at 28 to 30 days postpartum. ${ }^{19}$

- Oxygen/supplementary ventilation dependency at 36 weeks' postconceptional age. ${ }^{18}$

Currently the incidence of BPD is at around $30 \%$ for newborn babies with birth weights below $1,000 \mathrm{~g},{ }^{20}$ being less frequent among those over $1,250 \mathrm{~g}$ or born at gestational ages over 30 weeks. ${ }^{21}$ The etiology of BPD is multifactor and pulmonary inflammation contributes significantly to development. 14,22 Prolonged MV use with premature infants smaller than $1,250 \mathrm{~g}$ remains one of the primary factors responsible for the development of BPD.

Thus, BPD represents the extreme of the spectrum of pulmonary damage induced by prematurity and ante and postnatal events. However, significant losses of pulmonary function can also occur among premature infants who do not fulfill the criteria for BPD and who do not present significant respiratory disease during the neonatal period. ${ }^{23-25}$ Among these patients, the impact of prematurity on the respiratory system is often underestimated, in part as a result of the scarcity of clinical signs suggestive of lost pulmonary function, but also because of the limited possibilities for investigating that function during the first years of life.

\section{Clinical and functional respiratory progress in premature infants}

\section{Prematurity and respiratory disease - clinical studies}

The great majority of the original studies that assessed the respiratory outcomes of children born preterm in the $60 \mathrm{~s}$ and 70s did not find evidence of differences between premature infants who had and who had not been put on ventilatory support, nor between those with and without HMD or BPD, possibly due to the small number of premature infants that survived the neonatal period at that time. Thus it was not possible to assess the impact of each of these factors in isolation on the outcomes tested. Against this background, several different studies have described long term pulmonary findings in children born preterm, including increased incidence of pneumonia and bronchiolitis, 26 frequent re-hospitalizations for respiratory diseases, ${ }^{27-29}$ chronic and recurrent coughing and wheezing 29,30 bronchial hyperreactivity 29,31,32 and pulmonary function abnormalities, such as increased resistance, a propensity towards air trapping and reduced flow. 29,30,33-36

Kitchen et al. reported an increase in the risk of rehospitalizations and also in the number of days spent in hospital in premature infants of up to 5 years of age (principally during the first 2 years), with premature infants born with birth weights of less than $1,000 \mathrm{~g}$ exhibiting around three times more re-hospitalizations, compared with fullterm children. The principal causes of hospitalizations were respiratory infections (bronchitis, bronchiolitis, upper airway infections, pneumonia, acute otitis media and sore throats), and ear nose and throat surgery. Respiratory problems were shown to be the primary cause of morbidity in the premature group (40\%). Surprisingly, hospital admissions due to asthma were not more frequent for the premature infant group, and neither were the period on $\mathrm{MV}$ nor oxygen dependency $\left(\mathrm{O}_{2}\right)$ statistically associated with increased incidence of rehospitalizations among premature infants. ${ }^{28}$

Although some reports do exist of associations between prematurity and increased incidence of asthma during childhood, 37,38 other authors ${ }^{30}$ have failed to find a relationship between asthma, prematurity and perinatal factors, including respiratory disease at birth, when compared with fullterm children. Greenough et al. reported a high prevalence of respiratory symptoms in premature infants, being of the order of 47,36 and $33 \%$, for the first, second and third years of life respectively. ${ }^{39}$

Bronchopulmonary dysplasia survivors tend to present increased incidence rates of infections of the lower respiratory tract (bronchiolitis, pneumonia), when compared to premature infants with no BPD. Furthermore, increases were also demonstrated in the incidence rates of bronchitis (up to 2 years) and acute otitis media (from 2 to 5 years) in this population, when compared with premature infants without BPD and fullterm controls. 40

These children tend to be more susceptible to airway hyper-responsiveness and repeat respiratory infections, with an increased risk of hospitalizations during the first two years of life. ${ }^{21}$ Some of these patients exhibit severe lung disease, requiring MV and/or oxygen supplementation for months or years. 21

Premature infants with BPD, in particular if requiring home oxygen therapy, suffer negative repercussions to their somatic growth, with significant findings observed, with reduced weight and head circumference at 30 months in dysplastic premature infants on oxygen, when compared with those who had been discharged breathing normal air. This fact could be explained by the greater energy expenditure resulting from the respiratory disease and the concomitant feeding difficulties of these patients. ${ }^{41}$ Severe BPD also exhibits serious repercussions for the neurological development of premature infants and it has been demonstrated that this disease is an independent factor associated with cerebral palsy in surviving premature infants, in common with intracranial hemorrhage. 42

\section{Functional assessment during the first years of life}

The evaluation of the pulmonary functions of children less than 1 year of age was, until a few years ago, limited due to the absence of non-invasive tests that did not require such small patients to cooperate. The majority of studies used esophageal manometry and plethysmography of the whole body to measure pulmonary resistance and airways. ${ }^{43}$ These techniques are invasive, technically difficult to be performed, and require expensive material. Therefore, the technique known as rapid thoracic compression (or partial 
forced expiratory maneuvers - PFEM) and, later, a raised volume rapid thoracic compression (or full expiratory maneuvers $)^{44}$ were developed with success for small infants, demonstrated as reproducible and comparable to spirometry performed on large children and adults, with reference values having been described for a number of different age groups. $43-45$

Historically, the greater incidence of respiratory diseases observed in children born prematurely has been attributed to two factors: pulmonary immaturity and the intensity of the ventilatory support used during the neonatal period. ${ }^{29-}$ 31,33-36,46-48 McLeod et al. ${ }^{29}$ found an association between reduced flows and forced vital capacity (FVC) in premature infants who had needed MV for periods longer than 28 days and/or extended oxygen use at concentrations over $40 \%$ during neonatal hospital care.

However, recent cohort studies have suggested that gestational age $\mathrm{e}^{49-52}$ and birth weight and/or intrauterine growth restriction $30,34,46,50,53$ may be the more important determinants of childhood pulmonary function than intercurrent conditions suffered during the perinatal period. Rona et al. ${ }^{53}$ suggested that each extra week of gestation reduces the risk of later severe wheezing by $10 \%$. Nikolajev et al. 54 found reduced flow (but not volume) in children born small for gestational age (SGA), when compared with their appropriate for gestational age (AGA) twins. According to this hypothesis (called "disynaptic growth") intrauterine growth restriction would lead to an unbalanced pattern of pulmonary and airway growth, with the latter being narrow with respect of the parenchymal volume. These "abnormal" airways would be unable to keep up with the parenchyma's normal growth, thus resulting in reduced expiratory flow. 54 The major studies of pulmonary function in premature infants during their first years of life are listed in Table 1.

\section{Healthy preterms}

There are few studies in recently published literature evaluating premature infants with no neonatal respiratory diseases. ${ }^{49-51,55} \mathrm{~A}$ large proportion of the studies that are available were made of school aged children and adolescents, when they were already able to cooperate with spirometric tests. ${ }^{50,51,55}$ Furthermore, the majority of such research into children considered "healthy" who had been born prematurely, included babies who had required ventilatory assistance for short periods and also children who developed

Table 1 - Major studies of pulmonary function in premature infants

\begin{tabular}{|c|c|c|c|c|}
\hline Author & Patients & Age at PFT (corrected) & Method & Results \\
\hline Tepper et al. ${ }^{68}$ & $\begin{array}{l}20 \text { PMT with BPD } \\
111 \text { PMT } \\
\text { and healthy FTN }\end{array}$ & $\begin{array}{l}\text { Before discharge } \\
\text { and } 17 \text { months }\end{array}$ & $\begin{array}{l}\text { Helium dilution } \\
\text { Mixing index PFEM }\end{array}$ & $\begin{array}{c}\downarrow \text { Flows and mixing index } \\
\text { in BPD and worse in the } \\
\text { second test }\end{array}$ \\
\hline $\begin{array}{l}\text { Yuksel \& } \\
\text { Greenough24 }\end{array}$ & 21 healthy PMT & $\begin{array}{l}\text { 6-20 months } \\
2 \text { measures }\end{array}$ & $\begin{array}{l}\text { Plethysmography } \\
\text { Helium dilution }\end{array}$ & $\uparrow \mathrm{RSR}$ and RFC \\
\hline Merth et al. ${ }^{25}$ & $\begin{array}{l}26 \text { healthy PMT } \\
43 \text { FTN }\end{array}$ & 0-60 weeks & $\begin{array}{l}\text { Compliance } \\
\text { Helium dilution } \\
\text { Mixing index }\end{array}$ & $\begin{array}{l}\text { RSC, equal lung volumes } \\
\text { and mixing index } \\
\text { among groups }\end{array}$ \\
\hline Baraldi et al. ${ }^{70}$ & 24 PMT with BPD & $\begin{array}{c}10-20 \text { days of life } \\
3,6,9,12 \\
24 \text { months }\end{array}$ & $\begin{array}{l}\text { Single breath } \\
\text { N2 washout } \\
\text { PFEM }\end{array}$ & $\begin{array}{c}\text { Initially } \downarrow \text { RSC, } \uparrow \text { RSR } \\
\text { and } \downarrow \text { RFC, but normal } \\
\text { at the age of } 2 \text {. } \\
\text { Flows remain } \downarrow\end{array}$ \\
\hline Hoo et al. ${ }^{58}$ & 24 healthy PMT & $\begin{array}{l}3 \text { weeks } \\
\text { and } 1 \text { year }\end{array}$ & PFEM & $\begin{array}{l}\text { Normal flows } \\
\text { in the first test, } \\
\text { but } \downarrow \text { in the second }\end{array}$ \\
\hline $\begin{array}{l}\text { Hjalmarson \& } \\
\text { Sandberg }\end{array}$ & $\begin{array}{l}32 \text { healthy PMT } \\
53 \text { FTN }\end{array}$ & $\begin{array}{l}32-37 \text { weeks } \\
40 \text { weeks }\end{array}$ & $\begin{array}{l}\text { N2 washout } \\
\text { Compliance } \\
\text { Resistance }\end{array}$ & $\begin{array}{c}\text { PMT with } \downarrow \text { RFC, RSC and } \\
\text { gas mixing in both tests }\end{array}$ \\
\hline Robin et al. ${ }^{17}$ & 28 PMT with BPD & $<3$ years & $\begin{array}{c}\text { FFEM } \\
\text { Plethysmography }\end{array}$ & $\begin{array}{l}\text { BPD with } \downarrow \text { flows, } \\
\uparrow \text { RFC and RV. } \\
\text { Normal TLC }\end{array}$ \\
\hline
\end{tabular}

$\mathrm{PFT}=$ pulmonary function test $\mathrm{PMT}=$ premature $\mathrm{BPD}$ = bronchopulmonary dysplasia; $\mathrm{FTN}$ = full term newborn; mixing index = index of ventilation homogeneity; PFEM = partial forced expiratory maneuvers; RSR = respiratory system resistance; helium dilution = method for measuring pulmonary volumes; RFC = residual functional capacity; RSC = respiratory system compliance; FFEM = full forced expiratory maneuvers; RV = residual volume; TLC = total lung capacity . 
mild forms of CLDP. $49-51,55$ It has been demonstrated that a few minutes of ventilation with positive pressure are sufficient to trigger epithelial damage to the airways of immature newborns because they are more prone to lung injuries due to the immaturity of cellular junctions in their lungs, low antioxidant enzyme levels and low concentrations of factors that promote pulmonary differentiation and regeneration. 56,57 As a result of these limitations the majority of these studies were not capable of detecting whether the respiratory complications found in these populations were purely the result of prematurity in isolation or of the lung damage resulting from ventilatory support employed during the perinatal period. 50

Recently, some authors suggested that prematurity per se may be an independent risk factor for later pulmonary function abnormalities. $29,49,51,55,58$ Such abnormalities would be most obvious during the first years of life, becoming less evident over the following years. 23

The first twelve months of life are characterized by a high rate of somatic and, consequently, pulmonary growth, in addition to being the period during which the majority of childhood respiratory problems have onset, whether the result of intercurrent conditions suffered during the neonatal period or not. Since only the saccular phase of intrauterine pulmonary development is complete by 36 weeks' gestation, ${ }^{47}$ premature birth is associated with an interruption of the normal pulmonary development process and can result in abnormal lung and airway mechanical properties. Abnormal pulmonary function at an early age would explain the high levels of morbidity and mortality due to respiratory diseases in this population during the first year of life and could possibly be related with chronic obstructive abnormalities during adulthood.

Few recent studies were found that assessed the pulmonary function of healthy premature infants during the first months of life. Merth et al. ${ }^{25}$ measured respiratory system residual functional capacity (RFC) and compliance (RSC) in premature infants before 12 months, finding no differences comparing premature infants with fullterm babies when corrected postconceptional age was used. ${ }^{25}$

A study published in 2002 by Hjalmarson \& Sandberg, ${ }^{23}$ however, found significant reductions in RFC and RSC in premature infants at 40 weeks' postconceptional age, demonstrating dysfunction of terminal respiratory units and an increase in elastic recoil, compared with fullterm infants. These results would be the result of a changed period of alveolarization. Due to the fact that airway development precedes the development of alveoli and pulmonary microvasculature, parenchymal development disorders may be more severe than airway abnormalities when tested a short time after premature birth.

In 1992, Yuksel24 had already found increased airway resistance and of RFC in healthy premature infants at 6 and at 20 months corrected, suggesting that alveolar and airway development are abnormal in this subset of babies. The only study that has evaluated pulmonary flow in healthy premature infants during their first year of life was undertaken by Hoo et al., 58 who observed a significant reduction in $\mathrm{V}_{\max } \mathrm{FRC}$ (maximum flow at functional residual capacity) in healthy premature infants, compared with fullterm controls. Additionally, they observed worsening of expiratory flow over the first year of life. ${ }^{58}$ These results are controversial since the expectation would be for pulmonary function to improve as airways grow over the first years of life. Gappa et al. ${ }^{59}$ presented data on premature infants with and without BPD collected in three European countries (England, Germany and Norway), that also suggested reduced pulmonary function in this subset at 1 year of age, irrespective of the severity of subjacent disease or the mode of ventilation during the neonatal period. These data require confirmation in a larger prospective study, but emphasize the importance of serial pulmonary measurements, using a suitable control group when interpreting the long term effects of neonatal ventilatory management. 59

These studies by Hjalmarson \& Sandberg ${ }^{23}$ and Hoo et al. ${ }^{58}$ emphasized the importance of prematurity per se for subsequent pulmonary growth, allying themselves with Jobe's ${ }^{60}$ proposal that such children were, functionally, growing beyond their airways. The mechanisms subjacent to these observations remain the subject of speculation, but perhaps include the fact that maturation, dimensional growth and alveolar septation take place in a distinct manner after a premature birth, which could result in airways that are more compliant, smaller and/or with less alveoli "connections". 59 Such theories lead to the hypothesis that CLDP might be associated with chronic obstructive disease in periods after childhood. ${ }^{7}$ In conclusion: there is growing evidence that the reduction in pulmonary function that follows preterm birth could be related to developmental abnormalities, irrespective of the severity of initial disease and the effects of ventilatory therapies employed, and that antenatal care and prematurity prevention are as important for future pulmonary health over the long term as new improvements to ventilatory strategies during the neonatal period. 59

There still remain several gaps in our understanding of normal pulmonary growth and development and of the respiratory system's response to early insults. In contrast with survivors of BPD, HMD and MV, the pulmonary function of healthy premature infants has not yet been sufficiently studied, and little is known about how the process of pulmonary development and maturation of healthy premature human infants might be affected by prematurity in itself.

\section{Premature infants with BPD}

The functional consequences of BPD have been known for decades in older children, but the development of new techniques for assessing pulmonary function in infants has made its detection possible during the first years of life.

Even using a little sensitive technique, nitrogen washout, Gerhardt et al. ${ }^{61}$ observed a reduction in pulmonary compliance and conductance in children with BPD. Followingup the pulmonary function of these children by means of serial measurements appear to demonstrate progressive 
improvement, with improvements being described in compliance and conductance of 50 to $80 \%$ of that expected during the first years of life, achieving levels close to normal by three years of age. 61

Some studies, however, have recorded pulmonary function that remained abnormal throughout the first months or years of life. Hofhuis et al. found reduced expiratory flow at 6 and 12 months in dysplastic premature infants. 62 Tepper et al. ${ }^{43}$ compared children with BPD, healthy premature infants and fullterm infants at 1 year of age, by means of the rapid thoracic compression technique, finding that patients with dysplasia had a significant reduction in FVC and expiratory flow. The patients in this study, presented a progressive increase in FVC over the first year of life, although flow remained at half of normal by 17 months of age. In a similar manner, Mallory et al. ${ }^{63}$ observed that, during the first three years of age, vital capacity returned to normal, however severe lower airway obstruction persisted in all patients with moderate or severe BPD.

Taken together these results are consistent with the notion that lung and airway growth takes place according to the natural course of BPD, with progressive improvement in lung volumes, as the pulmonary parenchyma grows by means of alveolar multiplication, although substantial lower airway obstruction can remain.

In contrast with what has classically been conceived, some authors have not found differences in the prevalence of respiratory abnormalities when comparing newborns who needed $\mathrm{MV}$ or inhaled $\mathrm{O}_{2}$, and neither have they observed a significant relation between the PIP employed, the duration of $\mathrm{MV}$ and pulmonary function abnormalities. $34,50,51,64$ Coates et al. suggested that the reduction in flow could be explained by an increase in large airway resistance, probably secondary to premature birth, and that HMD and/or neonatal ventilatory treatments would provoke, by superimposition, an increase in small airway resistance, which could explain the increased incidence of obstructive diseases in this group as time goes on. ${ }^{36}$

\section{Functional assessment of children and adolescents}

\section{Premature children without BPD}

The majority of studies of pulmonary function performed of older children and adolescents born prematurely and considered "healthy" are of children born during the 70s and 80 s, during the pre-surfactant era, when the use of antenatal steroids was not routine either, and when, in addition to the elevated mortality, ventilatory therapies were significantly more aggressive because for a long time the concepts of lung damage from barotrauma, volutrauma or oxygen toxicity were unknown. These factors make the subset of premature infants that are being discharged from neonatal intensive care nowadays substantially different from those studied previously, both with respect of the degree of prematurity and of the treatment received during neonatal hospital care, making them difficult to compare.
Furthermore, the innumerable factors that determine pulmonary function in adulthood have cumulative effects and include not just perinatal factors, but also later adverse events. Thus, studies performed after childhood can have their results greatly influenced by environmental factors such as active or passive smoking, atmospheric pollution and viral infections, diluting the importance of prematurity as a risk factor for respiratory disease and masking its real impact during the first years of life.

Although some studies have demonstrated improvements in respiratory symptoms and even in pulmonary function as childhood and adolescence progress, $34,48,61,64-66$ there is increasing evidence that many abnormalities may persist until late childhood or even adulthood. $31,33,46,50,55,65,67,68$ Doyle, ${ }^{66}$ measuring the pulmonary function of premature infants born at less than $1,000 \mathrm{~g}$ at 14 years of age and comparing them with fullterm controls, reported that, while the incidence of symptoms and the prevalence of asthma and re-hospitalizations were similar for the two groups even for those who had BPD, expiratory flow was reduced for premature infants ( $32 \%$ versus $8 \%$ for the controls), with $22 \%$ exhibiting clinical repercussions. In contrast, variables representing pulmonary volume and air trapping were similar for the two groups. Chan et al. observed that, while compliance and total gas volume normalized during the first year of life (reflecting accelerated alveolar multiplication), conductance remained reduced during the following years, suggesting there had been little catch-up in airway caliber. ${ }^{69}$ Schraeder et al. did not find significant alterations to pulmonary function, respiratory symptoms and hyperreactivity in a group of premature infants (ventilated and not ventilated, dysplastic and non-dysplastic), tested at 10 to 11 years of age. Nevertheless, the subset of premature infants presented reduced pulmonary function when compared with fullterm children, although the results were not statistically significant, probably because of the small number of patients tested $(n=30)$. Furthermore, the questionnaires filled out by parents or guardians demonstrated more complicated previous respiratory histories among these children. ${ }^{48}$

The majority of the longitudinal follow-up studies have demonstrated improvements only in pulmonary volume, while expiratory flow generally remains abnormal throughout childhood and adolescence. There is, therefore, concern that there may be accelerated pulmonary function deterioration during adulthood, favoring the appearance of early chronic obstructive disease. 33,64

\section{Premature children with BPD}

The altered pulmonary function of children with a history of BPD is already a well-known fact. The majority of studies of patients presenting $\mathrm{HMD}^{46,50}$ and/or BPD $^{31-34,36,46,50,55,61,63,64,66-68,70-72 ~ h a v e ~ d e m o n s t r a t e d ~}$ an increase in the incidence of wheezing (up to $60 \%$ for 7-10 year-olds) ${ }^{65}$ and compromised pulmonary function, 35,66 with abnormalities that are primarily obstructive (hyperinflation, reduced compliance and increased resistance) during childhood and adolescence. 
In 2004, Robin et al. ${ }^{17}$ examined the pulmonary function of children with histories of BPD using complete forced expiratory maneuvers and observed a significant reduction in pulmonary function for the dysplastic group, characterized by mild to moderate obstructive signs (reduced flow) and air trapping, compared to normal fullterm controls. No statistically significant correlation was found between flow and birth weight, gestational age or days on $\mathrm{MV}$ or $\mathrm{O}_{2}$. Furthermore, $50 \%$ of the patients with a history of BPD had recurrent wheezing.

Jacob et al. reported reduced tolerance of exercise in 10 year-old children with a history of BPD. This subset use $93 \%$ of their reserve capacity during exercise, compared with $59 \%$ for a fullterm control group. ${ }^{73}$ Carbon monoxide transfer during rest and exercise was also reduced in BPD survivors, as was oxygen saturation, when compared with fullterm children and tested at 7 years of age, 74 probably reflecting a significant and persistent alteration in the development of gaseous exchange surface area. 60

Certain findings characteristic of BPD have been observed in histopathological studies of typical BPD cases, ${ }^{75}$ with reduced numbers of alveoli, thickening of the interalveolar septa, disarrangement of elastic and fibrous tissues, dilatation of ducti and alveolar hyperdistension, in addition to reduced caliber and hypertrophy of airway smooth muscle, atelectasis and capillary thickening. Similar findings, although less extensive, were also found in patients who had required only minimal positive pressure on MV. ${ }^{75}$ This constellation of damages would theoretically adversely affect pulmonary growth and development, leading to clinical and functional abnormalities observed later.

A number of different follow-up studies of BPD patients have demonstrated pulmonary alterations, including during adolescence and adulthood. ${ }^{76}$ Despite a relative improvement throughout childhood, 65 long-term followup of these children has revealed persistent pulmonary abnormalities, with reduced airflow, suggesting obstruction and airway hyper-responsiveness. ${ }^{77}$ The fact that these alterations persist could signify an addition of adverse effects related to preterm delivery summed with BPD at an age at which there is accelerated somatic growth, meaning that the airways are unable to keep up with the rate of growth. These results could, therefore, be the result of neonatal management, primarily the mode of assisted ventilation employed and the frequency of exposure (until a few years ago) to high doses of systemic steroids used to prevent or treat BPD cases. ${ }^{60}$ It is now known that corticosteroids delay and change the process of alveolarization in the developing lungs. Small premature infants who suffered fatal outcomes due to BPD, present, at autopsy, extremely "simplified" lungs, with increased size and significantly reduced numbers of alveoli, in addition to the dysplastic vasculature. These abnormalities appear to persist for months in animals exposed to excessive MV. ${ }^{78}$

The principal studies of pulmonary function in premature infants during childhood and adolescence are listed in Table 2.

Table 2 - Major studies of pulmonary function in premature infants during childhood and adolescence

\begin{tabular}{|c|c|c|c|c|}
\hline Author & Patients & Age at TFP & Method & Main results \\
\hline Coates et al. ${ }^{36}$ & $\begin{array}{l}7 \text { PMT with MV } \\
7 \text { PMT without } \mathrm{O}_{2} \\
7 \text { FTN }\end{array}$ & 6-10 years & $\begin{array}{c}\text { Spirometry } \\
\text { Plethysmography }\end{array}$ & $\begin{array}{c}\downarrow \text { flows in all PMT } \\
\text { (specially MV and BPD) }\end{array}$ \\
\hline Smyth et al. 67 & 9 PMT with BPD & 8 years & $\begin{array}{c}\text { Spirometry, } \\
\text { bronchial stimulation, } \\
\text { plethysmography, Helium dilution }\end{array}$ & $\begin{array}{c}\text { PMT with } \uparrow \text { RV/TLC, } \\
\downarrow \text { flows and } \\
\uparrow \text { hyperreactivity }\end{array}$ \\
\hline Mansell et al. 49 & $\begin{array}{c}26 \text { healthy PMT } \\
18 \text { PMT with MV + HMD } \\
18 \text { FTN }\end{array}$ & $5-9$ years & $\begin{array}{c}\text { Spirometry, } \\
\text { plethysmography, } \\
\text { Helium dilution, N2 washout }\end{array}$ & $\begin{array}{l}\text { Two PMT groups with similar } \\
\text { flows and conductance, } \\
\text { but } \downarrow \text { as compared to FTN }\end{array}$ \\
\hline Galdès-Sebaldt et al. ${ }^{51}$ & $\begin{array}{l}49 \text { PMT } \\
24 \text { FTN }\end{array}$ & $10-13$ years & $\begin{array}{l}\text { Spirometry, } \\
\text { bronchial stimulation, } \\
\text { CMD, Plethysmography }\end{array}$ & $\begin{array}{l}\text { PMT with air trapping } \\
\text { and } \downarrow \text { flows; } \\
\uparrow \mathrm{HB} ; \downarrow \text { CMD in PMT }\end{array}$ \\
\hline Kitchen et al. ${ }^{34}$ & $\begin{array}{l}209 \text { PMT } \\
60 \text { FTN }\end{array}$ & 8 years & $\begin{array}{l}\text { Spirometry, } \\
\text { plethysmography }\end{array}$ & $\begin{array}{c}\text { PF similar to FTN and not } \\
\text { associated to perinatal events }\end{array}$ \\
\hline
\end{tabular}

$\mathrm{PFT}=$ pulmonary function test $\mathrm{PMT}=$ premature $; \mathrm{MV}=$ mechanical ventilation; $\mathrm{FTN}=$ full term newborn; $\mathrm{BPD}=$ bronchopulmonary dysplasia; helium dilution = method for measuring pulmonary volumes; $\mathrm{RV}=$ residual volume; $\mathrm{TLC}=$ total lung capacity; $\mathrm{HMD}=$ hyaline membrane disease; $\mathrm{CMD}=\mathrm{carbon}$ monoxide diffusion; $\mathrm{PF}=$ pulmonary flow; $\mathrm{C}_{\mathrm{L}}=$ lung compliance; $\mathrm{R}_{\mathrm{L}}=$ lung resistance; $\mathrm{WT}=$ weight at term; $\mathrm{GA}=$ gestational age; $\mathrm{NS}=$ non significant.

(Table 2 continues on the next page) 
Table 2 - Major studies of pulmonary function in premature infants during childhood and adolescence (continuation)

\begin{tabular}{|c|c|c|c|c|}
\hline Author & Patients & Age at TFP & Method & Main results \\
\hline Rona et al. 53 & 2,036 PMT and FTN & $6,5-11$ years & Spirometry & $\begin{array}{l}\text { Low weight at term } \\
\text { associated to flow reduction }\end{array}$ \\
\hline Parat et al. 55 & $\begin{array}{c}15 \text { PMT with BPD } \\
9 \text { healthy PMT } \\
10 \text { FTN }\end{array}$ & $7-10$ years & $\begin{array}{l}\text { Spirometry, test } \\
\text { exercise LC e LR } \\
\text { and Helium dilution }\end{array}$ & $\begin{array}{c}\uparrow \mathrm{R}_{\mathrm{L}^{\prime}} \downarrow \mathrm{C}_{\mathrm{L}} \text { and } \downarrow \text { flows in BPD and, } \\
\text { in a lowest degree, } \\
\text { in PMT without BPD; } \\
\text { slight intolerance to exercises }\end{array}$ \\
\hline Hakulinen et al. 46 & $\begin{array}{l}20 \text { PMT with BPD } \\
11 \text { PMT with DPC } \\
20 \text { FTN }\end{array}$ & 7-11 years & $\begin{array}{l}\text { Spirometry, } \\
\text { plethysmography, } \\
\text { CMD }\end{array}$ & $\begin{array}{l}\text { PMT (all) with } \downarrow \text { flows } \\
\text { and diffusion capacity; } \\
\text { normal volumes. } \\
\downarrow \text { CMD in PMT }\end{array}$ \\
\hline McLeod et al. ${ }^{29}$ & $\begin{array}{l}292 \text { PMT } \\
574 \text { FTN }\end{array}$ & $8-9$ years & $\begin{array}{c}\text { Spirometry, } \\
\text { Exercise tolerance }\end{array}$ & $\begin{array}{l}\text { Flows and volumes } \downarrow \text { in PMT, } \\
\text { more hiperreactivity; } \\
\text { association with MV and } \mathrm{O}_{2} \text {, } \\
\text { but not with WT and GA }\end{array}$ \\
\hline Pelkonen et al. ${ }^{31}$ & $\begin{array}{c}12 \text { PMT with BPD } \\
17 \text { PMT without BPD } \\
22 \text { FTN }\end{array}$ & $8-14$ years & $\begin{array}{c}\text { Spirometry, } \\
\text { Bronchial stimulation }\end{array}$ & $\begin{array}{c}\text { PMT with } \downarrow \text { flows } \\
\text { (specially those with BPD); } \\
\text { more hiperreactive BPD }\end{array}$ \\
\hline Giacoia et al. 40 & $\begin{array}{c}12 \text { PMT with BPD } \\
12 \text { PMT without BPD } \\
12 \text { FTN }\end{array}$ & School-age & Spirometry & $\begin{array}{c}\text { BPD with } \downarrow \text { flows; } \\
\text { PMT without BPD with } \downarrow \text { flows, } \\
\text { though NS }\end{array}$ \\
\hline Jacob et al. ${ }^{72}$ & $\begin{array}{c}15 \text { PMT with BPD } \\
15 \text { PMT without BPD }\end{array}$ & School-age & $\begin{array}{l}\text { Spirometry } \\
\text { Plethysmography }\end{array}$ & $\begin{array}{c}\text { BPD with } \downarrow \text { flows, } \\
\text { RFC and } \uparrow \mathrm{RV} ; \text { similar volumes }\end{array}$ \\
\hline Schraeder et al. ${ }^{48}$ & $\begin{array}{l}30 \text { PMT } \\
45 \text { FTN }\end{array}$ & 10-11 years & $\begin{array}{c}\text { Spirometry, } \\
\text { Bronchial stimulation }\end{array}$ & $\begin{array}{c}\text { PMT with } \downarrow \text { flows and } \\
\uparrow \text { hiperreactivity, though NS }\end{array}$ \\
\hline Doyle et al. ${ }^{64}$ & $\begin{array}{c}67 \text { PMT < } 1 \mathrm{~kg} \\
86 \text { PMT } 1-1.5 \mathrm{~kg}\end{array}$ & 8 e 14 years & $\begin{array}{l}\text { Spirometry, } \\
\text { plethysmography }\end{array}$ & $\begin{array}{c}\text { With progressive improvement, } \\
\text { but PMT with smaller flows; } \\
\text { normal volumes }\end{array}$ \\
\hline
\end{tabular}

$\mathrm{PFT}=$ pulmonary function test $\mathrm{PMT}=$ premature $\mathrm{MV}=$ mechanical ventilation; $\mathrm{FTN}=$ full term newborn; $\mathrm{BPD}=$ bronchopulmonary dysplasia; helium dilution = method for measuring pulmonary volumes; $\mathrm{RV}=$ residual volume; $\mathrm{TLC}=$ total lung capacity; $\mathrm{HMD}=$ hyaline membrane disease; $\mathrm{CMD}=\mathrm{carbon}$ monoxide diffusion; $\mathrm{PF}=$ pulmonary flow; $\mathrm{C}_{\mathrm{L}}=$ lung compliance; $\mathrm{R}_{\mathrm{L}}=$ lung resistance; $\mathrm{WT}=$ weight at term; $\mathrm{GA}=$ gestational age; $\mathrm{NS}=$ non significant.

\section{Final considerations}

Prematurity and the events that provoke the interventions consequent to prematurity permanently alter, to lesser or greater degrees, respiratory system development. The study of the influence of these events on the genesis of CLDP is an important theme in neonatology and pediatric pneumology. Assessments of the impact of pre and postnatal exposures on short-term respiratory health are facilitated by the recent emergence of objective techniques for measuring pulmonary function in infants. ${ }^{44}$ The pattern of growth and development of the airways and pulmonary parenchyma during the first year of life in premature infants has not yet been well defined. Better understanding of the functional alterations to the respiratory system that take place during growth is essential to determine how it is that perinatal insults can produce acute and chronic damage to the airways and pulmonary parenchyma and, potentially, to propose better strategies for prevention and treatment of chronic lung disease during childhood. 43

\section{References}

1. Hack M, Friedman H, Fanaroff AA. Outcomes of extremely low birth weight infants. Pediatrics. 1996;98:931-7.

2. Doyle L. Outcome at 5 years of age of children of 23 to 27 weeks' gestation: refining the prognosis. Pediatrics. $2001 ; 108$ : 134-41.

3. Coalson JJ. Pathology of new bronchopulmonary dysplasia. Semin Neonatol. 2003;8:73-81.

4. Bancalari E, Claure N, Sosenko IR. Brochopulmonary dysplasia: changes in pathogenesis, epidemiology and definition. Semin Neonatol. 2003;8:63-71.

5. Fenton A, Mason E, Clarke M, Field D. Chronic lung disease following neonatal ventilation - II. Changing incidence in a geographically defined population. Pediatr Pulmonol. 1996;21:24-7.

6. Speer C, Silverman M. Issues relating to children born prematurely. Eur Respir J. 1998;12:13-6.

7. Eber $E$, Zach M. Long term sequelae of bronchopulmonary dysplasia (chronic lung disease of infancy). Thorax. 2001;56: 317-23.

8. Thurlbeck W. Postnatal growth and development of the lung. Am Rev Respir Dis. 1975;111:803-44.

9. Thurlbeck W. Prematurity and the developing lung. Clin Perinatol. 1992;19:497-518. 
10. Stick S. The contribution of airway development to paediatric and adult lung disease. Thorax. 2000;55:587-94.

11. Albertine K, Jones G, Starcher B, Bohnsack J, Davis P, Cho S, et al. Chronic lung injury in preterm lambs - disordered respiratory tract development. Am J Respir Crit Care Med. 1999;159:945-58.

12. Kotecha S, Silverman M. Chronic complications of prematurity. In: Taussig LM, Landau LI, editors. Pediatric Respiratory Medicine. St. Louis: Mosby; 1999. p. 488-520.

13. Bancalari E. Changes in the pathogenesis and prevention of chronic lung disease of prematurity. Am J Perinatol. 2001;18:1-9.

14. Northway Jr WH, Rosan RC, Porter DY. Pulmonary disease following respirator therapy of hyaline-membrane disease. Bronchopulmonary dysplasia. New Engl J Med. 1967;276:357-68.

15. Bancalari E, Abdenour G, Feller R, Gannon J. Bronchopulmonary dysplasia: clinical presentation. J Pediatr. 1979;95:819-23.

16. Charafeddine L, D'Angio CT, Phelps DL. Atypical chronic lung disease patterns in neonates. Pediatrics. 1999;103:759-65.

17. Robin B, Kim Y, Huth J, Klocksieben J, Torres M, Tepper RS, et al. Pulmonary function in bronchopulmonary dysplasia. Pediatr Pulmonol. 2004;37:236-42.

18. Shenann AT, Dunn MS, Ohlsson A, Lenoox K, Hoskins EM. Abnormal pulmonary outcomes in premature infants: prediction from oxygen requirement in the neonatal period. Pediatrics. 1988;82:527-32.

19. Hansen TW, Wallach M, Dey AN, Boivin P, Vohr B, Oh W. Prognostic value of clinical and radiologic status on day 28 of life for subsequent course in very low birthweight $(<1500 \mathrm{~g})$ babies with bronchopulmonary dysplasia. Pediatr Pulmonol. 1993;15:327-31.

20. Stevenson DK, Wright LL, Lemons J, Oh W, Korones SB, Papile LA, et al. Very low birth weight outcomes of the National Institute of Child Health and Human Development Neonatal Research Network, January 1993 through December 1994. Am J Obstet Gynecol. 1998;179:1632-9.

21. Jobe AH, Bancalari E. Bronchopulmonary dysplasia. Am J Respir Crit Care Med. 2001;163:1723-9.

22. Northway Jr WH. Bronchopulmonary dysplasia: then and now. Arch Dis Child. 1990;65:1076-81.

23. Hjalmarson $\mathrm{O}$, Sandberg K. Abnormal lung function in healthy preterm infants. Am J Respir Crit Care Med. 2002;165:83-7.

24. Yuksel B, Greenough A. Lung function in 6-20 month old infants born very preterm but without respiratory troubles. Pediatr Pulmonol. 1992;14:214-21.

25. Merth I, de Winter J, Borsboom G, Quanjer P. Pulmonary function during the first year of life in healthy infants born prematurely. Eur Respir J. 1995;8:1141-7.

26. Stahlman M, Hedvall G, Dolanski E, Faxelius G, Burko H, Kirk V. A six-year follow-up of clinical hyaline membrane disease. Pediatr Clin North Am. 1973;20:433-46.

27. McCormick MC, Workman DK, Brooks-Gunn J, Peckham GJ. Hospitalization of very low birthweight children at school age. J Pediatr. 1993;122:360-5.

28. Kitchen W, Ford G, Doyle L, Rickards A, Kelly E. Health and hospital readmissions of very low birthweight and normal birthweight children. Am J Dis Child. 1990;144:2213-8.

29. McLeod A, Ross P, Mitchell S, Tay D, Hunter A, Paton J, et al. Respiratory health in a total very low birthweight cohort and their classroom controls. Arch Dis Child. 1996;74:188-94.

30. Chan KN, Elliman A, Bryan E, Silverman M. Respiratory symptoms in children of low birth weight. Arch Dis Child. 1989;64:1294-304.

31. Pelkonen A, Hakulinen A, Turpeinen M. Bronchial ability and responsiveness in school children born very preterm. Am J Respir Crit Care Med. 1997;156:1178-84.

32. Chan KN, Elliman A, Bryan E, Silverman M. Clinical significance of airway responsiveness in children of low birth weight. Pediatr Pulmonol. 1989;7:251-8.

33. Andréasson $B$, Lindroth $M$, Mortensson $W$, Svenningsen $N$, Jonson B. Lung function eight years after neonatal ventilation. Arch Dis Child. 1989;64:108-13.

34. Kitchen WH, Olinsky A, Doyle LW, Ford GW, Murton LJ, Slonim $L$, et al. Respiratory health and lung function in 8-year-old children of very low birth weight: a cohort study. Pediatrics. 1992;89:1151-8.

35. Stocks J, Godfrey S. The role of artificial ventilation, $\mathrm{O} 2$ and CPAP in the pathogenesis of lung damage in neonates, assessed by serial measurements of lung function. Pediatrics. $1976 ; 57: 352-62$.
36. Coates $A L$, Bergsteinsson $H$, Desmond $K$, Outerbridge $E W$, Beaudry $\mathrm{PH}$. Long term pulmonary sequelae of premature birth with and without idiopathic respiratory distress syndrome. J Pediatr. 1977;90:611-6.

37. Elder D, Hagan R, Evans S, Benninger H, French N. Recurrent wheezing in very preterm infants. Arch Dis Child. 1996;76: 165-71.

38. Kelly $Y$ J, Brabin BJ, Milligan P, Heaf DP, Reid J, Pearson MG. Maternal asthma, premature birth, and the risk of respiratory morbidity in schoolchildren in Mereyside. Thorax. 1995;50: 525-30.

39. Greenough A, Giffin FJ, Yuksel B. Respiratory morbidity in preschool children born prematurely. Relationship to adverse neonatal events. Acta Paediatr. 1996;85:772-7.

40. Giacoia GP, Venkataraman PS, West-Wilson KI, Faulkner MJ. Follow-up of school-age children with bronchopulmonary dysplasia. J Pediatr. 1997;130:400-8.

41. Wood NS, Costeloe K, Gibson AT, Hennessy EM, Marlow N, Wilkinson AR. The EPICure study: growth and associated problems in children born at 25 weeks of gestational age or less. Arch Dis Child Fetal Neonatal Ed. 2003;88:492-500.

42. Palta M, Sadek-Badawi M, Evans M, Weinstein MR, McGuinness G. Functional assessment of a multicenter very low-birth-weight cohort at age 5 years. Arch Pediatr Adolesc Med. 2000;154:23-30.

43. Tepper RS, Morgan WJ, Cota K, Wright A, Taussig LM. Physiologic growth and development of the lung during the first year of life. Am Rev Respir Dis. 1986;134:513-9.

44. Jones M, Castile R, Davis S, Kisling J, Filbrun D, Flucke R, et al. Forced expiratory flows and volumes in infants - normative data and lung growth. Am J Respir Crit Care Med. 2000;161:353-9.

45. Tepper RS, Reister T. Forced expiratory flows and lung volumes in normal infants. Pediatr Pulmonol. 1993;15:357-61.

46. Hakulinen $A$, Järvenpää $A$, Turpeinen $M$, Sovijärvi A. Diffusing capacity of the lung in school-aged children born very preterm, with and without bronchopulmonary dysplasia. Pediatr Pulmonol. $1996 ; 21: 353-60$

47. Kotecha S. Lung growth: implications for the newborn infant. Arch Dis Child Fetal Neonatal Ed. 2000;82:69-74.

48. Schraeder B, Czajka C, Kalman D, McGeady S. Respiratory health, lung function, and airway responsiveness in school-age survivors of very-low-birth-weight. Clin Pediatr. 1998;37:237-46.

49. Mansell A, Driscoll J, James L. Pulmonary follow-up of moderately low birth weight infants with and without respiratory distress syndrome. J Pediatr. 1987;110:111-5.

50. Chan K, Noble-Jamieson C, Elliman A, Bryan E, Silverman M. Lung function in children of low birth weight. Arch Dis Child. 1989;64:1284-93.

51. Galdès-Sebaldt M, Sheller J, Grogaard J, Stahlman M. Prematurity is associated with abnormal airway function in childhood. Pediatr Pulmonol. 1989;7:259-64.

52. Yuksel B, Greenough A. Neonatal respiratory support and lung function abnormalities at follow-up. Respir Med. 1992;86:97-100.

53. Rona R, Gulliford M, Chinn S. Effects of prematurity and intrauterine growth on respiratory health and lung function in childhood. BMJ. 1993;306:817-20.

54. Nikolajev $\mathrm{K}$, Heinonen $\mathrm{H}$, Hakulinen A, Lansimies E. Effects of intrauterine growth retardation and prematurity on spirometric flow values and lung volumes at school age in twin pairs. Pediatr Pulmonol. 1998;25:367-70.

55. Parat S, Moriette G, Delaperche M, Escourrou P, Denjean A, Gaultier C. Long-term pulmonary functional outcome of bronchopulmonary dysplasia and premature birth. Pediatr Pulmonol. 1995;20:289-96.

56. Groneck P, Götze-Speer B, Oppermann M, Eiffert H, Speer C. Association of pulmonary inflammation and increased microvascular permeability during the development of bronchopulmonary dysplasia: a sequential analysis of inflammatory mediators in respiratory fluids of high-risk preterm neonates. Pediatrics. 1994;93:712-8.

57. Pierce $M$, Bancalari $E$. The role of inflammation in the pathogenesis of bronchopulmonary dysplasia. Pediatr Pulmonol. 1995;19: 371-8.

58. Hoo A, Dezateux C, Costeloe K, Stocks J. Development of airway function in infancy after preterm delivery. J Pediatr. 2002;141:652-8.

59. Gappa M, Stocks J, Merkus P. Lung growth and development after preterm birth - further evidence [Letter to the Editor]. Am J Respir Crit Care Med. 2003;168:399-400. 
60. Jobe $\mathrm{AH}$. An unknown: lung growth and development after very preterm birth [Editorial]. Am J Respir Crit Care Med. 2002; 166:1529-30.

61. Gerhardt T, Hehre D, Feller R, Reifenberg L, Bancalari E. Serial determination of pulmonary function in infants with chronic lung disease. J Pediatr. 1987;110:448-56.

62. Hofhuis W, Huysman MW, van der Wiel EC, Holland WP, Hop WC, Brinkhorst $G$, et al. Worsening of $V^{\prime}$ maxFRC in infants with chronic lung disease in the first year of life: a more favorable outcome after high-frequency oscillation ventilation. Am J Respir Crit Care Med. 2002;166:1539-43.

63. Mallory G, Chaney H, Mutich R, Motoyama E. Longitudinal changes in lung function during the first three years of premature infants with moderate to severe bronchopulmonary dysplasia. Pediatr Pulmonol. 1991;11:8-14.

64. Doyle LW, Chavasse R, Ford GW, Olinsky A, Davis NM, Callanan C. Changes in lung function between age 8 and 14 years in children with birth weight of less than $1,501 \mathrm{~g}$. Pediatr Pulmonol. 1999;27:185-90.

65. Blayney M, Kerem E, Whyte H, O'Brodovich H. Bronchopulmonary dysplasia: improvement in lung function between 7 and 10 years of age. J Pediatr. 1991;118:201-6.

66. Doyle LW. Growth and respiratory health in adolescence of the extremely low-birth weight survivor. Clin Perinatol. 2000;27: 421-33.

67. Smyth J, Tabachnik E, Duncan W, Reilly B, Levison H. Pulmonary function and bronchial hyperreactivity in long-term survivors of bronchopulmonary dysplasia. Pediatrics. 1981;68:336-40.

68. Tepper R, Morgan W, Cota K, Taussig L. Expiratory flow limitation in infants with bronchopulmonary dysplasia. J Pediatr. 1986;109:1040-6.

69. Chan KN, Wong YC, Silverman M. Relationship between lung mechanics and childhood lung function in children of very low birthweight. Pediatr Pulmonol. 1990;8:74-81.

70. Baraldi E, Fillipone M, Trevisanuto D, Zanardo V, Zacchello F. Pulmonary function until two years of life in infants with bronchopulmonary dysplasia. Am J Respir Crit Care Med. 1997; 155:149-55.
71. Merth I, de Winter J, Zonderland H, Borsboom G, Quanjer P. Pulmonary function in infants with neonatal chronic lung disease with or without hyaline membrane at birth. Eur Respir J. 1997; 10:1606-13.

72. Jacob S, Coates A, Lands L, MacNeish C, Riley S, Hornby L, et al. Long-term pulmonary sequelae of severe bronchopulmonary dysplasia. J Pediatr. 1998;133:193-200.

73. Jacob SV, Lands LC, Coates AL, Davis GM, MacNeish CF, Hornby $L$, et al. Exercise ability in survivors of severe bronchopulmonary dysplasia. Am J Respir Crit Care Med. 1997;155:1925-9.

74. Mitchell SH, Teague WG. Reduced gas transfer at rest and during exercise in school-age survivors of bronchopulmonary dysplasia. Am J Respir Crit Care Med. 1998;157:1406-12.

75. Margraf L, Tomashefski J, Bruce M, Dahms B. Morphometric analysis of the lung in bronchopulmonary dysplasia. Am Rev Respir Dis. 1991;143:391-400.

76. Northway Jr WH, Moss RB, Carlisle KB, Parker BR, Popp RL, Pitlick PT, et al. Late pulmonary sequelae of bronchopulmonary dysplasia. N Engl J Med. 1990;323:1793-9.

77. Sadeghi $H$, Lowenthal D, Dozor AJ. Inspiratory flow limitation in children with bronchopulmonary dysplasia. Pediatr Pulmonol. $1998 ; 26: 167-72$

78. Coalson JJ, Winter V, deLemos RA. Decreased alveolarization in baboon survivors with bronchopulmonary dysplasia. Am J Respir Crit Care Med. 1995;152:640-6.

Correspondence:

Marcus Jones

Hospital São Lucas - Instituto de Pesquisas Biomédicas (IPB)

Av. Ipiranga, 6690

CEP 90610-000 - Porto Alegre, RS

Brazil

E-mail: mhjones@pucrs.br 